\title{
Non-invasive assessment of shunt and ventilation/perfusion ratio in neonates with pulmonary failure
}

\author{
H L Smith, J G Jones
}

Cambridge University Department of Anaesthesia, Addenbrooke's Hospital, Cambridge, UK

H L Smith

J G Jones

Correspondence to: Professor Jones, Department of Anaesthesia, Cambridge University, Level 4, Addenbrooke's Hospital, Cambridge CB2 2QQ, UK gareth@garjons.demon.co.uk

Accepted 14 May 2001

\begin{abstract}
Aims-To make non-invasive measurements of right to left (R-L) shunt and reduced ventilation/perfusion ratio $\left(V_{A} / Q\right)$ in neonates with pulmonary failure and to examine sequential changes in these variables after treatment.

Methods-Twelve neonates with pulmonary failure were studied. They ranged in gestational age from 24 to 37 (median 27) weeks and were 1-39 (median 4) days old. Shunt and reduced $V_{A} / Q$ were derived from their effects on the relation between inspired oxygen pressure $\left(\mathrm{PIO}_{2}\right)$ and arterial oxygen saturation measured with a pulse oximeter $\left(\mathrm{Spo}_{2}\right)$. Pairs of $\mathrm{PIO}_{2} v \mathrm{Spo}_{2}$ data points were obtained by varying $\mathrm{PIO}_{2}$ in a stepwise fashion. A computer algorithm based on a model of pulmonary gas exchange fitted a curve to these data. With $\mathrm{PIO}_{2}$ on the abscissa, an increase in shunt produced a downward movement of the curve, whereas reducing $\mathrm{V}_{\mathrm{A}} / \mathrm{Q}$ to $<0.8$ shifted the curve to the right. The right shift gives a variable that is inversely related to $\mathrm{V}_{\mathrm{A}} / \mathbf{Q}$, the $\mathbf{P I O}_{2}-\mathbf{P}_{\overline{\mathrm{c}}} \mathrm{o}_{2}$ difference, where $\mathbf{P}_{\bar{c}} \mathrm{O}_{2}$ is mixed capillary oxygen pressure.

Results-Ten of the 12 infants on the first study day had large shunts (range 5.9$31.0 \%$, median $19.9 \%$, normal $<8 \%$ ) and large $\mathbf{P I O}_{2}-\mathbf{P}_{\bar{c}} \mathrm{O}_{2}$ differences (range 9.7$64.4 \mathrm{kPa}$, median $19.8 \mathrm{kPa}$, normal $<7$ $\mathrm{kPa}$ ) equivalent to a median $\mathrm{V}_{\mathrm{A}} / \mathrm{Q}$ of 0.2 (normal median $V_{A} / Q=0.8$ ). Sequential improvement in shunt and $V_{A} / Q$ were shown in most infants after treatment.
\end{abstract}

Sudden large changes in these variables were shown in two infants.

Conclusion-This simple non-invasive method distinguishes between shunt and reduced $V_{A} / Q$ in neonates with pulmonary failure.

(Arch Dis Child Fetal Neonatal Ed 2001;85:F127-F132)

Keywords: shunt; $\mathrm{V}_{\mathrm{A}} / \mathrm{Q}$; non-invasive; oxygen saturation

A reduced ventilation/perfusion ratio $\left(\mathrm{V}_{\mathrm{A}} / \mathrm{Q}\right)$ and an increased shunt cause quite different, but characteristic, effects on the relation between inspired oxygen pressure $\left(\mathrm{PIO}_{2}\right)$ and arterial oxygen saturation $\left(\mathrm{SaO}_{2}\right) .{ }^{12} \mathrm{~A}$ reduced $\mathrm{V}_{\mathrm{A}} / \mathrm{Q}$ in the absence of shunt reduces both alveolar oxygen $\left(\mathrm{PAO}_{2}\right)$ and oxygen saturation but increasing the $\mathrm{PIO}_{2}$ washes out alveolar nitrogen, restores $\mathrm{PAO}_{2}$, and corrects desaturation. In contrast, an isolated shunt reduces oxygen saturation, but increasing $\mathrm{PIO}_{2}$ does not correct this because the shunted blood is never exposed to the increased $\mathrm{PIO}_{2}$. The nonshunted blood is almost fully saturated, and even administering $100 \%$ oxygen adds only a small amount of dissolved oxygen, which cannot compensate for the effect of the shunt.

It may be important in neonates to differentiate between a reduced $\mathrm{V}_{\mathrm{A}} / \mathrm{Q}$ and a shunt. For example, in an animal model of surfactant deficiency when surfactant was administered into the airways either as a bolus or as an aerosol, $\mathrm{V}_{\mathrm{A}} / \mathrm{Q}$ worsened with the former but improved with the latter. ${ }^{3}$ There may also be a prognostic significance of different degrees of

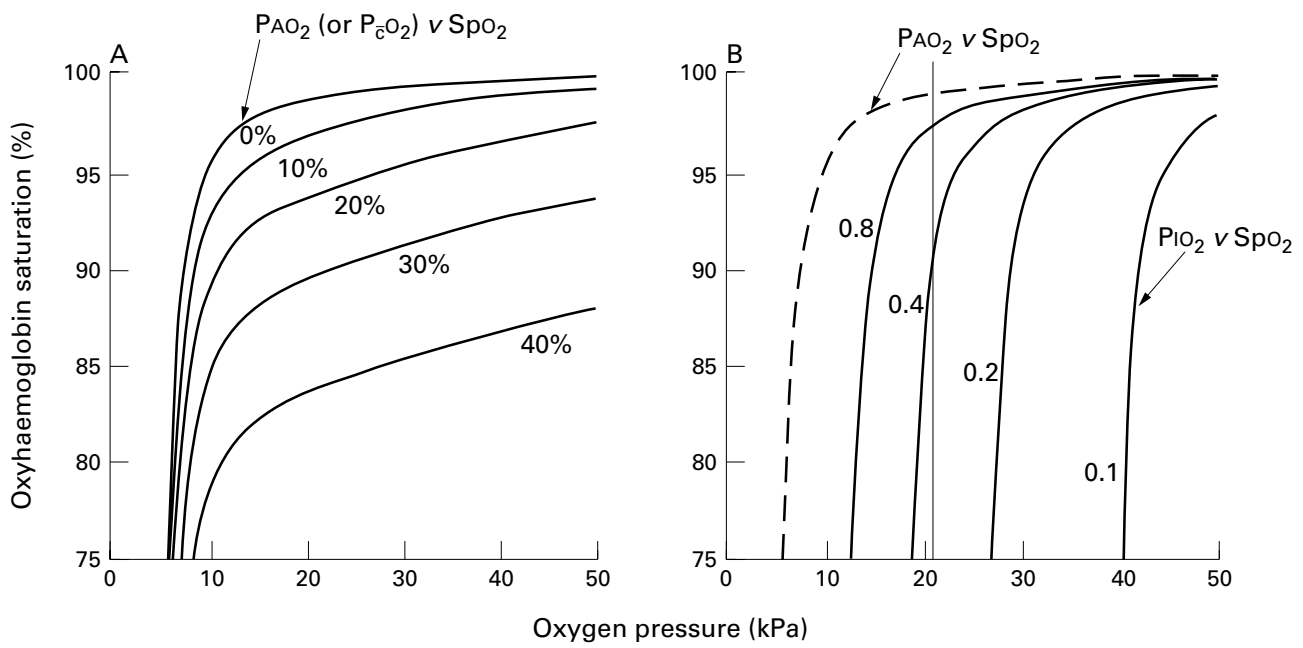

Figure 1 (A) Increasing shunt (from 0 to $40 \%$ ) lowers the curve. (B) Reducing $V_{A} / Q$ from 0.8 to 0.1 shifts the curve to the right. The right shift of each $\mathrm{PIO}_{2} v$ Spo curve from the position of the dissociation curve (dashed line) is the $P_{I} \mathrm{O}_{2}-P_{\bar{c}} \mathrm{O}_{2}$ difference in $\mathrm{kPa}$ which includes $\mathrm{PaCO}_{2} / \mathrm{R}$. The 0.8 curve represents the normal lung which intercepts a $P_{I O}$ of $21 \mathrm{kPa}$ (vertical line) at $97 \% \mathrm{SpO}_{2}$. 
Table 1 Summary of the clinical information on the first day of the study

\begin{tabular}{|c|c|c|c|c|}
\hline $\begin{array}{l}\text { Patient } \\
\text { code }\end{array}$ & $\begin{array}{l}\text { Days after } \\
\text { delivery }\end{array}$ & $\begin{array}{l}\text { Gestation } \\
\text { (weeks) }\end{array}$ & $\begin{array}{l}\text { Birth } \\
\text { weight }(\mathrm{kg})\end{array}$ & Admission diagnosis \\
\hline$\overline{\mathrm{A}}$ & 4 & 37 & 3.94 & $\begin{array}{l}\text { Parvovirus infection } \\
\text { Anaemia } \\
\text { Hydramnios }\end{array}$ \\
\hline B & 33 & 28 & 0.86 & RDS \\
\hline $\mathrm{C}$ & 8 & 27 & 0.69 & $\begin{array}{l}\text { RDS } \\
\text { Surfactant } \times 2\end{array}$ \\
\hline $\mathrm{D}$ & 3 & 31 & 1.0 & $\begin{array}{l}\text { RDS } \\
\text { Surfactant } \times 3\end{array}$ \\
\hline $\mathrm{E}$ & 2 & 27 & 0.86 & $\begin{array}{l}\text { RDS } \\
\text { Surfactant } \times 4\end{array}$ \\
\hline $\mathrm{F}$ & 39 & 29 & 0.84 & RDS \\
\hline G & 7 & 31 & 1.56 & $\begin{array}{l}\text { RDS } \\
\text { Surfactant }\end{array}$ \\
\hline $\mathrm{H}$ & 1 & 26 & 0.82 & $\begin{array}{l}\text { RDS } \\
\text { Surfactant }\end{array}$ \\
\hline I & 4 & 26 & 0.68 & $\begin{array}{l}\text { RDS } \\
\text { Surfactant }\end{array}$ \\
\hline $\mathrm{J}$ & 26 & 27 & 0.82 & $\begin{array}{l}\text { RDS } \\
\text { Surfactant }\end{array}$ \\
\hline $\mathrm{K}$ & 1 & 24 & 0.55 & $\begin{array}{l}\text { RDS } \\
\text { Surfactant }\end{array}$ \\
\hline $\mathrm{L}$ & 3 & 24 & 0.71 & $\begin{array}{l}\text { RDS, PDA } \\
\text { Surfactant }\end{array}$ \\
\hline
\end{tabular}

RDS, Respiratory distress syndrome; PDA, patent ductus arteriosus.

$\mathrm{V}_{\mathrm{A}} / \mathrm{Q}$ and shunt. However, existing methods of quantifying the relative contributions to oxygen desaturation of $\mathrm{V}_{\mathrm{A}} / \mathrm{Q}$ and shunt are not suitable for routine clinical application in neonates. ${ }^{4-8}$

We have described ${ }^{129}$ a simple non-invasive method for the calculation of shunt and reduced $\mathrm{V}_{\mathrm{A}} / \mathrm{Q}$ in adults which entails the simultaneous measurement of two variables, the inspired oxygen partial pressure $\left(\mathrm{PIO}_{2}\right)$ and oxyhaemoglobin saturation using pulse oximetry $\left(\mathrm{SpO}_{2}\right)$. By changing the inspired oxygen partial pressure, pairs of $\mathrm{PIO}_{2}$ and $\mathrm{Spo}_{2}$ values are obtained. The curve relating $\mathrm{PIO}_{2}$ to $\mathrm{Spo}_{2}$ reflects the shape of the dissociation curve but always lies to the right, and its shape and position vary considerably when gas exchange is impaired. ${ }^{12}{ }^{9-11}$ Thus, with $\mathrm{PIO}_{2}$ on the abscissa:

- Increasing the shunt from 0 to $40 \%$ displaces the $\mathrm{PIO}_{2} v \mathrm{SpO}_{2}$ curve downwards (fig 1A). This reflects the inability of an increase in $\mathrm{PIO}_{2}$ to compensate for an increase in shunt.

- Reducing $\mathrm{V}_{\mathrm{A}} / \mathrm{Q}$ from 0.8 to 0.1 shifts the curve to the right (fig $1 \mathrm{~B}$ ) because the oxygen gradient increases between $\mathrm{PIO}_{2}$ and $\mathrm{PAO}_{2}$ (or $\mathrm{P}_{\bar{c}} \mathrm{O}_{2}$, the mixed capillary oxygen). Increasing alveolar $\mathrm{CO}_{2}$ also shifts the curve to the right by $\mathrm{PCO}_{2} / \mathrm{R}$, where $\mathrm{R}$ is the gas exchange ratio. The right shift due to $\mathrm{PCO}_{2} / \mathrm{R}$ is small, typically $6 \mathrm{kPa}$, compared with the effect of reducing $\mathrm{V}_{\mathrm{A}} / \mathrm{Q}$ from 0.8 to 0.1 , which causes a shift of $28 \mathrm{kPa}$.

- Note that, in fig $1 \mathrm{~B}$, the $\mathrm{PIO}_{2} v \mathrm{SpO}_{2}$ curve representing a $\mathrm{V}_{\mathrm{A}} / \mathrm{Q}$ of 0.8 corresponds to the curve in normal subjects and gives an $\mathrm{SpO}_{2}$ of $97 \%$ breathing air.

We studied a group of neonates with pulmonary failure to see if we could derive shunt and $\mathrm{V}_{\mathrm{A}} / \mathrm{Q}$ from the $\mathrm{PiO}_{2} v \mathrm{Spo}_{2}$ data pairs despite the expected circulatory and ventilatory instabilities in such infants. We then examined the day to day changes to see if we could show

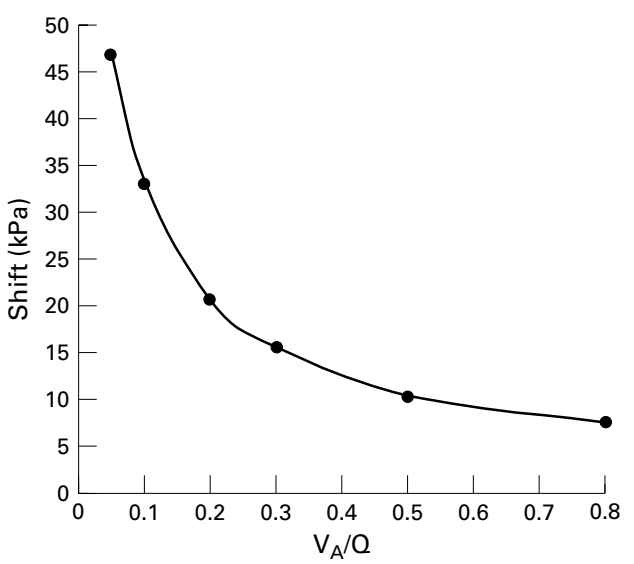

Figure 2 Inverse relation between $V_{A} / Q$ and the right shift of the $\mathrm{PIO}_{2} v \mathrm{SpO}_{2}$ curve.

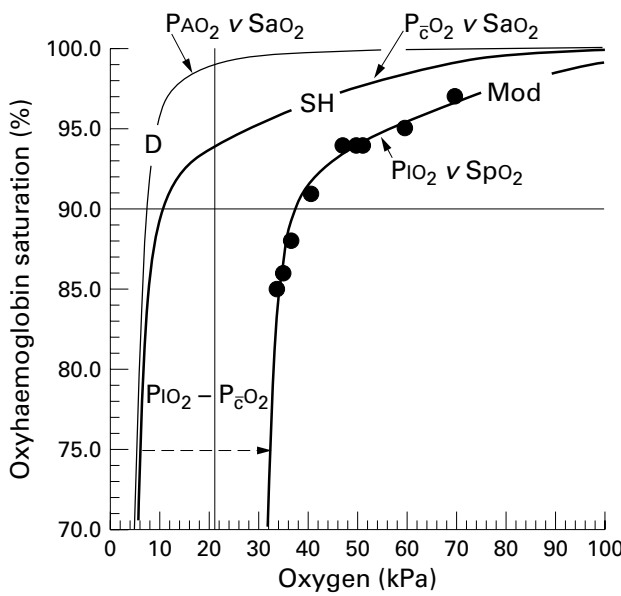

Figure 3 Example of data analysis from infant I. Curve $D$, the dissociation curve, corresponds to a $0 \%$ shunt (see fig $1 A$ ) and curve $S H$ to a $21.6 \%$ shunt. When curve $S H$ is moved to the right by a $\mathrm{PIO}_{2}-\mathrm{P}_{\mathrm{O}_{2}}$ difference of $26.6 \mathrm{kPa}$ (dashed arrow), it superimposes the data points (closed circles) to give curve Mod.

sequential improvements in shunt and $V_{A} / Q$ with continuing treatment.

\section{Methods}

PATIENTS

Twelve neonates, each with pulmonary failure requiring mechanical ventilation, were studied after local ethics committee approval had been obtained and informed consent obtained from the parents. In seven of these babies, up to four repeat studies were performed at intervals of up to 23 days.

The babies were being treated in the Neonatal Intensive Care Unit, Rosie Maternity Hospital, Addenbrooke's Hospital, Cambridge. All but one of the infants were preterm with intrauterine growth retardation and were admitted for ventilation for respiratory distress syndrome (table 1). All infants were being ventilated through a tracheal tube. A consultant neonatologist not involved in this study managed ventilatory support. One infant, delivered at 37 weeks gestation (infant A), had developed hydrops foetalis after parvovirus infection in utero. In most infants, surfactant had been administered when appropriate through a tracheal tube. Arterial blood gas and 
Table 2 Details of shunt and right shift of the $\mathrm{PIO}_{2} v \mathrm{SpO}_{2}$ curve

\begin{tabular}{llllll}
\hline Patient & Shunt $(\%)$ & $\begin{array}{l}\text { Shunt } 95 \% \mathrm{CI} \\
(\%)\end{array}$ & $\begin{array}{l}\text { Shift }(\mathrm{kPa}), \\
\left(V_{A} / Q\right)\end{array}$ & $\begin{array}{l}\text { Shift } 95 \% \mathrm{CI} \\
(\mathrm{kPa})\end{array}$ & $r^{2}$ \\
\hline A 4 & 30.7 & 29.3 to 32.2 & $64.4(<0.05)$ & 61.8 to 67.1 & 0.73 \\
A 5 & 27.3 & 26.4 to 28.3 & $16.8(0.27)$ & 14.5 to 19.1 & 0.78 \\
A 10 & 20.1 & 18.6 to 21.8 & $11.4(0.49)$ & 8.3 to 14.5 & 0.89 \\
B & 10.8 & 7.8 to 13.7 & $13.5(0.4)$ & 11.5 to 15.6 & 0.83 \\
C & 20.1 & 18.2 to 21.9 & $17.5(0.25)$ & 16.1 to 18.8 & 0.8 \\
D & 17.1 & 16.0 to 18.2 & $19.8(0.2)$ & 18.7 to 20.8 & 0.93 \\
E 2 & 19.7 & 17.0 to 22.5 & $58.5(<0.05)$ & 55.1 to 61.9 & 0.92 \\
E 3 & 23.1 & 22.3 to 23.8 & $26.9(0.14)$ & 25.5 to 28.4 & 0.86 \\
E 9 & 23.5 & 22.7 to 24.3 & $56.2(<0.05)$ & 55.2 to 57.1 & 0.93 \\
E 25 & 16.1 & 13.2 to 18.8 & $29.0(0.13)$ & 26.8 to 31.3 & 0.72 \\
F 39 & 26.5 & 25.6 to 27.5 & $34.6(0.1)$ & 31.5 to 37.7 & 0.97 \\
F 43 & 11.2 & 9.3 to 13.2 & $10.3(0.5)$ & 7.1 to 13.5 & 0.94 \\
G & 21.5 & 20.2 to 22.8 & $19.1(0.2)$ & 16.2 to 21.95 & 0.92 \\
H 1 & 31.0 & 30.0 to 32.0 & $53.9(<0.05)$ & 50.5 to 57.3 & 0.99 \\
H 4 & 5.9 & 5.0 to 6.7 & $9.7(0.55)$ & 9.0 to 10.4 & 0.99 \\
I 4 & 21.6 & 20.8 to 22.4 & $26.6(0.15)$ & 24.9 to 28.2 & 0.96 \\
I 8 & 7.3 & 5.3 to 9.2 & $13.7(0.4)$ & 13.4 to 14.1 & 0.93 \\
J 26 & 13.3 & 11.8 to 14.7 & $22.9(0.18)$ & 22.2 to 23.5 & 0.93 \\
J 27 & 19.0 & 18.0 to 20.0 & $22.0(0.18)$ & 22.5 to 23.5 & 0.95 \\
K & 28.0 & 27.0 to 28.8 & $14.2(0.35)$ & 12.2 to 16.2 & 0.97 \\
L 3 & 17.1 & 16.1 to 18.0 & $18.6(0.22)$ & 17.6 to 19.5 & 0.95 \\
L 7 & 18.4 & 17.6 to 19.2 & $19.7(0.2)$ & 17.9 to 21.5 & 0.96 \\
\hline
\end{tabular}

$\mathrm{V}_{\mathrm{A}} / \mathrm{Q}$ is the ventilation to perfusion ratio in the ventilated but poorly perfused compartment and was derived from the mean shift- that is, $\mathrm{PIO}_{2}-\mathrm{P}_{\bar{c}} \mathrm{O}_{2}$ in $\mathrm{kPa}$ - using fig 2 . The number after the patient code is the number of days after birth for repeat studies. $r^{2}$ indicates the goodness of fit of the gas exchange model to the $\mathrm{PIO}_{2} v \mathrm{SpO}_{2}$ data points. ${ }^{9}$

haemoglobin values were recorded independently as part of routine clinical management. Monitoring included measurement of inspired oxygen concentration and arterial saturation using the integral gas analyser in the Draeger Babylog 8000 ventilator (to give $\mathrm{FIO}_{2}$ or $\mathrm{PIO}_{2}$ ) and an Ohmeda Biox 3700e pulse oximeter (to give $\left.\mathrm{SpO}_{2}\right)$. The Draeger automatically calibrates itself every 24 hours-for example, at
1100 , using piped air and $100 \%$ oxygen. Each calibration takes 90 seconds and the instrument is accurate to $5 \%$ full scale deflectionthat is, $21(1) \mathrm{kPa}$. The instrument sounds an alarm if the calibration exceeds this range. The routine arterial blood gas results were used periodically to check the pulse oximeter reading. Pulse oximeters are accurate to $\pm 1 \%$ in the normal range but much less at low $\mathrm{SpO}_{2}$ (see Discussion)

\section{PROCEDURE}

$\mathrm{PIO}_{2}$ was varied in steps to cause the $\mathrm{SpO}_{2}$ to vary between $85 \%$ and $96 \%$. This level of oxygen has been used in previous research in the measurement of cerebral blood flow using near infrared spectroscopy. ${ }^{12}$ The $\mathrm{PiO}_{2}$ was never reduced below $21 \mathrm{kPa}$.

DATA ANALYSIS AND INTERPRETATION

The pairs of $\mathrm{PIO}_{2}$ and $\mathrm{SpO}_{2}$ data points for each study were recorded and analysed using a computer algorithm which gave a curve representing a single solution for each subject's data set. ${ }^{9}$ This curve is not a statistical line of best fit but is based on a model of gas exchange used by the computer algorithm to describe the $\mathrm{PIO}_{2} v \mathrm{SpO}_{2}$ data points by two variables of gas exchange:

- virtual shunt using the shunt equation;

- the difference between inspired oxygen and mixed pulmonary capillary oxygen pressures $\left(\mathrm{PIO}_{2}-\mathrm{P}_{\overline{\mathrm{c}}} \mathrm{O}_{2}\right)$, a function of reduced $\mathrm{V}_{\mathrm{A}} / \mathrm{Q}$ and $\mathrm{PCO}_{2} / \mathrm{R}$.
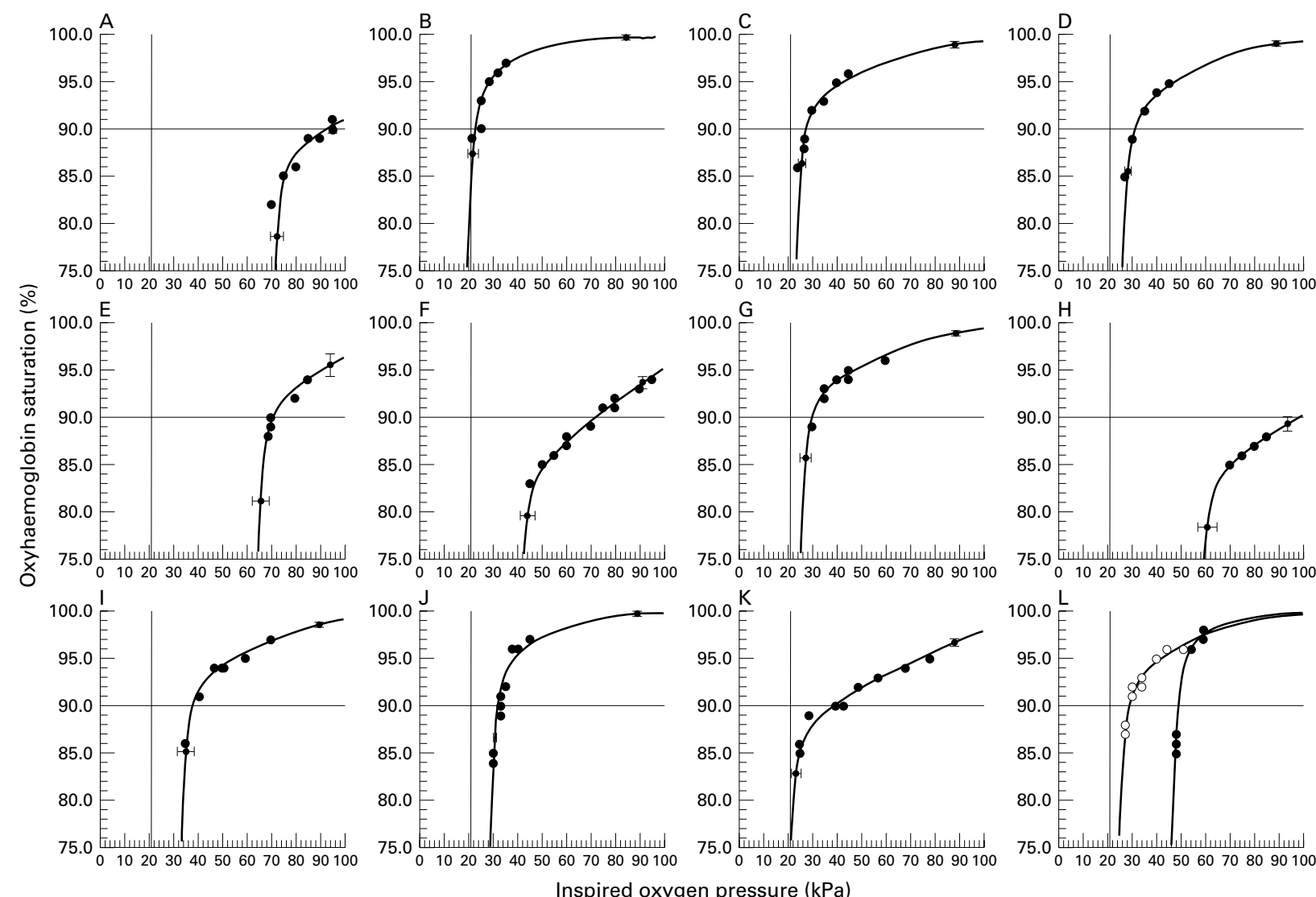

Inspired oxygen pressure $(\mathrm{kPa})$

Figure 4 The $\mathrm{PIO}_{2} v \mathrm{SpO} \mathrm{O}_{2}$ curves from all 12 infants on the first day that they were studied. In every case the curve is shifted to the right of the line marking a $\mathrm{PIO}_{2}$ of $21 \mathrm{kPa}$, indicating a large reduction in $V_{A} / Q$ ratio. In infant $L$, there are two data sets, before (closed circles) and after tracheal aspiration (open circles). 

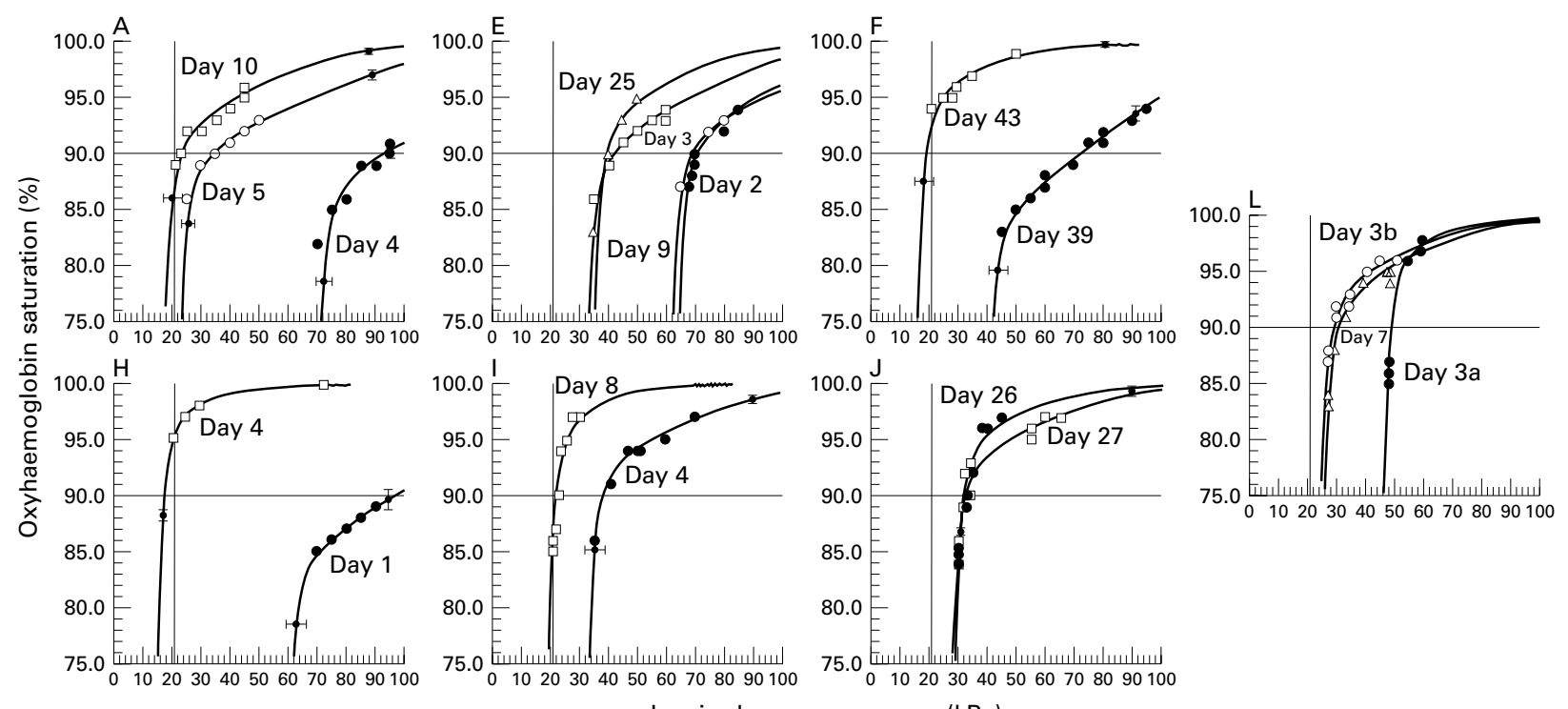

Figure 5 Sequence of changes in $\mathrm{PIO}_{2} v \mathrm{SpO}_{2}$ data points and model fit in seven infants who were studied sequentially.

Figure 2 gives the inverse relation between right shift - that is, $\mathrm{PIO}_{2}-\mathrm{P}_{\bar{c}} \mathrm{O}_{2}$ - and $\mathrm{V}_{\mathrm{A}} / \mathrm{Q}$.

The term "virtual" is used if shunt and $\mathrm{V}_{\mathrm{A}} / \mathrm{Q}$ are calculated with assumed values of haemoglobin, carbon dioxide $\left(\mathrm{PCO}_{2}\right)$, respiratory quotient $(\mathrm{R})$, and arteriovenous oxygen difference when the actual values are not available. In this study, $\mathrm{R}$ and arteriovenous oxygen difference were assumed.

\section{Results}

Table 1 shows the admission diagnosis, gestational age, days after delivery, and weight of the 12 infants.

Figure 3 shows a $\mathrm{PIO}_{2} v \mathrm{Spo}_{2}$ data set from infant I on the first study day (closed circles). A model curve (Mod) was fitted to these data by the computer algorithm which calculated a shunt value of $21.6 \%$. A $21.6 \%$ shunt is shown by curve $\mathrm{SH}$ which, in the absence of $\mathrm{V}_{\mathrm{A}} / \mathrm{Q}$ abnormality, asymptotes the dissociation curve $\mathrm{D}$ as shown in fig 3 . The algorithm fits the $\mathrm{SH}$ curve to the data points by displacing it to the right of $\mathrm{D}$ by $26.6 \mathrm{kPa}$. This displacement is the $\mathrm{PIO}_{2}-\mathrm{P}_{\bar{c}} \mathrm{O}_{2}$ difference, which represents the combined effects of a reduced $\mathrm{V}_{\mathrm{A}} / \mathrm{Q}$ plus $\mathrm{PCO}_{2} / \mathrm{R}$.

Table 2 gives the calculated values of shunt and right shift $\left(\mathrm{PIO}_{2}-\mathrm{P}_{\bar{c}} \mathrm{O}_{2}\right)$ for all these infants on the first study day. This also shows the $\mathrm{V}_{\mathrm{A}} / \mathrm{Q}$ derived from $\mathrm{PIO}_{2}-\mathrm{P}_{\bar{c}} \mathrm{O}_{2}$ and the $r^{2}$ value, which is the goodness of fit of the model to the data points. ${ }^{9}$

The values for shunt and right shift- that is, $\mathrm{PIO}_{2}-\mathrm{P}_{\bar{c}} \mathrm{O}_{2}$ difference and thus $\mathrm{V}_{\mathrm{A}} / \mathrm{Q}$ - for each baby shown in table 2 all showed a good fit to the $\mathrm{PIO}_{2} v \mathrm{SpO}_{2}$ data points indicated by the $r^{2}$ value. ${ }^{9}$ Figure 4 shows these data points and the computed curves for all 12 infants on the first study day. All these data are plotted on a grid where vertical and horizontal lines mark a $\mathrm{PIO}_{2}$ of $21 \mathrm{kPa}$ (air at sea level) and an $\mathrm{SpO}_{2}$ of $90 \%$ respectively. Note that the normal curve, with a median $\mathrm{V}_{\mathrm{A}} / \mathrm{Q}$ of 0.8 , intersects the 21 $\mathrm{kPa}$ line at about $97 \% \mathrm{Spo}_{2}$, and this is equivalent to moving the dissociation curve (D in fig
3) to the right by about $6-7 \mathrm{kPa}$-for example, a normal $\mathrm{PCO}_{2} / \mathrm{R}$. The $95 \%$ confidence intervals of the fit of the curve are shown for shunt (upper part of the curve) and right lateral shift (lower part of the curve).

Note that in every case the curve was shifted to the right of the vertical line marking a $\mathrm{PIO}_{2}$ of $21 \mathrm{kPa}$ (air at sea level). There was a good fit of the curve to the data points despite the considerable shunt and right shift, the most severe examples of which were in infants A, E, F, and $\mathrm{H}$. Two curves are shown for infant $\mathrm{L}$. The one on the right was recorded first and that on the left 20 minutes after tracheal suction (see discussion).

Seven babies were studied on more than one occasion (fig 5). Infant $\mathrm{A}$, a neonate with hydrops foetalis secondary to anaemia following an intrauterine parvovirus infection, showed a considerable improvement from day 4 to day 5 , and this improvement continued to day 10 . The overall reduction in shunt was from $30.7 \%$ to $20.1 \%$. More dramatically there was a decrease in $\mathrm{PIO}_{2}-\mathrm{P}_{\overline{\mathrm{c}}} \mathrm{O}_{2}$ from $64.4 \mathrm{kPa}$ to $11.4 \mathrm{kPa}$, equivalent to an improvement in $\mathrm{V}_{\mathrm{A}} / \mathrm{Q}$ from less than 0.05 to 0.49 .

Infant $\mathrm{E}$ showed a very unstable clinical pattern with improvement (day 2 to day 3) followed by deterioration (day 3 to day 9). Eventually (day 25) there was the lowest value of shunt, $16.1 \%$, but there was still a very large right shift-that is, a large $\mathrm{PIO}_{2}-\mathrm{P}_{\bar{c}} \mathrm{O}_{2}$ difference-which our gas exchange model equated to the perfused alveoli having a $V_{A} / Q$ of 0.13 .

Infants $\mathrm{F}$ and $\mathrm{H}$ showed a considerable improvement over the days they were studied, with a reduction in both the shunt and right shift to near normal values.

Infant I, a 26 week old neonate with infant respiratory distress syndrome, was the only baby studied while dependent on a high frequency oscillator. From day 4 to day 8 there was an improvement in both shunt and right shift (figs 4 and 5 and table 2). The shunt 
decreased from $21.6 \%$ to $7.3 \%$ (normal), with the right shift being reduced from $26.6 \mathrm{kPa}$ to $13.7 \mathrm{kPa}$ - that is, $\mathrm{a} \mathrm{V}_{\mathrm{A}} / \mathrm{Q}$ of 0.14 improving to 0.4 .

Infant $\mathrm{J}$ showed deterioration in shunt from day 26 to 27 . A normal echo ruled out a patent ductus arteriosus. However, this baby was hypotensive and had suspected necrotising enterocolitis. Infant L showed a more stable picture, with little change between days 3 and 7.

\section{Discussion}

Our gas exchange model derives two variables of impaired gas exchange: shunt and the $\mathrm{PIO}_{2}-\mathrm{P}_{\bar{c}} \mathrm{O}_{2}$ difference representing the effect of a reduced $\mathrm{V}_{\mathrm{A}} / \mathrm{Q}\left(0.05<\mathrm{V}_{\mathrm{A}} / \mathrm{Q}<1\right)$. In all 12 infants, we found a good fit of the model to the $\mathrm{PIO}_{2} v \mathrm{SpO}_{2}$ data points. With a few exceptions the curves were stable - that is, a single shunt equation fitted all the $\mathrm{PIO}_{2} v \mathrm{Spo}_{2}$ data points obtained from one subject during one data collection period. The results were similar to those seen in a variety of adult patients with pulmonary failure during anaesthesia, ${ }^{9}$ thoracotomy, ${ }^{10}$ and after fat embolism. ${ }^{11}$

Reducing median $\mathrm{V}_{\mathrm{A}} / \mathrm{Q}$ below unity causes a considerable increase in oxygen gradient. ${ }^{1}$ However, some workers, as recently as 1995, have assumed that the entire oxygen gradient is explained only by a shunt. ${ }^{1314}$ This simplistic approach ignores the effect of an altered $\mathrm{V}_{\mathrm{A}} / \mathrm{Q}$ distribution on the oxygen gradient and lumps together the effects of a reduced $\mathrm{V}_{\mathrm{A}} / \mathrm{Q}$ with those of a shunt. In infants with respiratory distress syndrome, ${ }^{45}$ the nitrogen gradient method shows a considerable reduction in $\mathrm{V}_{\mathrm{A}} / \mathrm{Q}$, which explains about $30 \%$ of the oxygen gradient. ${ }^{5}$ Not only were $\mathrm{V}_{\mathrm{A}} / \mathrm{Q}$ ratios as low as 0.05 , but also, in one case, this accounted for almost the whole of an oxygen gradient of $65 \mathrm{kPa}^{5}$ This large gradient is similar in magnitude to the $\mathrm{PIO}_{2}-\mathrm{P}_{\bar{c}} \mathrm{O}_{2}$ difference seen in our infant $\mathrm{A}$ (table 2), which gave a $\mathrm{V}_{\mathrm{A}} / \mathrm{Q}$ of 0.05

In some of our infants, the increase in shunt $(>30 \%)$ and reduction in $\mathrm{V}_{\mathrm{A}} / \mathrm{Q}(<0.05)$ were considerable, the gas exchange abnormalities being as great as those previously seen during thoracic anaesthesia in adults in whom a considerable part of the lung was collapsed. ${ }^{10}$

Some infants showed considerable variability in the $\mathrm{PiO}_{2} v \mathrm{Spo}_{2}$ data. Three examples are as follows. (a) Infant $\mathrm{L}$ at the start of the data collection period showed a very large reduction in $\mathrm{V}_{\mathrm{A}} / \mathrm{Q}$ causing a right shift of $40 \mathrm{kPa}$ but with a very small shunt (fig 4 ). After tracheal aspiration, there was an improvement in $\mathrm{V}_{\mathrm{A}} / \mathrm{Q}$ but with an increase in shunt from 6.6 to $17 \%$ (open circles fig 4). (b) In infant J, there were two episodes of sudden hypoxaemia when the $\mathrm{SpO}_{2}$ fell precipitously necessitating the inspired oxygen concentration to be increased to $60 \%$. These episodes may have been caused either by a transient opening of an R-L shunt or, more likely, a fall in cardiac output causing an increased shunt effect. ${ }^{9}(c)$ At times, in an otherwise stable data set, there was more than $6 \%$ variability in $\mathrm{SpO}_{2}$. This was particularly so when we were measuring $\mathrm{SpO}_{2}$ on the steep part of the $\mathrm{PIO}_{2} v \mathrm{SpO}_{2}$ curve. This was consistent with our previous observations in postoperative adult patients ${ }^{15}$, for whom we reported a very unstable pattern of $\mathrm{SpO}_{2}$ when the $\mathrm{PIO}_{2}$ lay on the steep part of the $\mathrm{PIO}_{2} v \mathrm{SpO}_{2}$ curve.

Severinghaus and Naifeh ${ }^{16}$ examined the accuracy of pulse oximeters. They found that the probe is accurate to $\pm 1 \%$ in the normal range, but, with a sudden hypoxic episode, an $\mathrm{SpO}_{2}$ reading of $55 \%$ may be $7 \%$ lower than the actual $\mathrm{SaO}_{2}$ value. Because such inaccuracy occurs only on the very steep part of the oxyhaemoglobin dissociation curve, this has little effect on the derivation of the $\mathrm{PIO}_{2} v$ curve in our studies. The derived $\mathrm{PIO}_{2} v \mathrm{SpO}_{2}$ curve based on our model of gas exchange obviously does not fit every data point, and the $r^{2}$ value and the $95 \%$ confidence interval of shunt and right shift of the curve describe this variability (table 2).

The fetal dissociation curve is shifted to the left of the adult curve with a $\mathrm{P}_{50}$ of $2.7 \mathrm{kPa}$ compared with the adult value of $3.6 \mathrm{kPa}$. This difference is reduced after birth and after blood transfusion. This means that the median value of the variable $\mathrm{PiO}_{2}-\mathrm{P}_{\mathrm{C}} \mathrm{O}_{2}$, which for the whole study was $19.8 \mathrm{kPa}$, would have been underestimated by less than $1 \mathrm{kPa}$.

The model is sensitive to a reduced haemoglobin concentration and low cardiac output. ${ }^{9}$ The haemoglobin value for each infant was recorded from routine samples taken on the day of the study, and these values were used in the calculation of shunt and $\mathrm{V}_{\mathrm{A}} / \mathrm{Q}$. A cardiac output equivalent to an arteriovenous oxygen difference of $5 \mathrm{ml} / \mathrm{dl}$ was assumed.

We conclude that the method shows that the gas exchange model based on the oxyhaemoglobin dissociation curve provides a good fit to the $\mathrm{PIO}_{2} v \mathrm{SpO}_{2}$ data in the circumstances of our study. The model gave a non-invasive measurement of shunt and reduced $\mathrm{V}_{\mathrm{A}} / \mathrm{Q}$ in neonates during mechanical ventilation and allowed the prediction of the effect on $\mathrm{SpO}_{2}$ of changing $\mathrm{PIO}_{2}$.

We thank Drs James Powell and Jackie Gedney for their assistance with this study. Dr Wilf Kelsall was consultant neonatologist at Addenbrooke's hospital in whose care were the infants described in this paper.

1 Roe PG, Jones JG. Analysis of factors which affect the relationship between inspired oxygen partial pressure and arterial oxygen saturation. Br $\mathcal{F}$ Anaesth 1993;71:488-94.

2 Sapsford DJ, Jones JG. Predicting changes in oxygen saturation using pulse oximetry. Br F Anaesth 1988;61:497P.

3 Schermuly RT, Gunther A, Weissman N, et al. Differential impact of ultrasonically nebulized versus tracheal-instilled surfactant on ventilation-perfusion $\left(\mathrm{V}_{\mathrm{N}} \mathrm{O}\right)$ mismatch in a model of acute lung injury. Am 7 Respir Crit Care Med 2000;161:152-9.

4 Corbet AJS, Ross JA, Beaudry PH, et al. Ventilationperfusion relationships as assessed by aADN $\mathrm{An}_{2}$ in hyaline membrane disease. F Appl Physiol 1974;36:74-81.

5 Hand IL, Shepard EK, Krauss AN, et al. Ventilationperfusion abnormalities in the preterm infant with hyaline membrane disease: a two-compartment model of the neonatal lung. Pediatr Pulmonol 1990;9:206-13.

6 Thibeault DW, Poblete E, Auld PAM. Alveolar-arterial oxygen difference in premature infants breathing 100 percent oxygen. F Pediatr 1967;71:814-24.

7 Roca J, Wagner PD. Principles and information content of the multiple inert gas elimination technique. Thorax 1993;49:815-24.

8 Melot C. Ventilation-perfusion relationships in acute respiratory failure. Thorax 1994;49:1251-8. 
9 Sapsford DJ, Jones JG. The $\mathrm{PiO}_{2}$ vs. $\mathrm{SpO}_{2}$ diagram: a non-invasive measure of pulmonary oxyen exchange. Eur 7 Anaesth 1995;12:375-86.

10 de Gray L, Rush EM, Jones JG. A non-invasive method for evaluating the effecy of thoracotomy on shunt and ventilation perfusion inequality. Anaesthesia 1997;52:630-5.

11 Burnstein RM, Newell JP, Jones JG. Sequential changes in gas exchange following traumatic fat embolism. Anaesthesia 1998;53:369-81.

12 Edwards AD, Wyatt JS, Richardson C, et al. Cotside measurement of cerebral blood flow in infants by near infrared spectroscopy. Lancet 1988;2:770-1.
13 Lawler PGP, Nunn JF. A reassessment of the validity of the iso-shunt graph. Br $\mathcal{F}$ Anaesth 1984:56:1325-35.

14 Hope DA, Jenkins BJ, Willis $\mathrm{N}$, et al. Non-invasive estimation of venous admixture: validation of a new formula. Br F Anaesth 1995;74:538-43.

15 Roe PG, Gadelrab R, Sapsford D, et al. Intra operative gas exchange and post operative hypoxaemia. Eur $\mathcal{F}$ Anaesth 1997;14:203-10.

16 Severinghaus JW, Naifeh KH. Accuracy of response of six pulse oximeters to profound hypoxia. Anesthesiology $1987 ; 67: 551-8$ 